\title{
PENGARUH PENAMBAHAN PATI TALAS (Colocasia esculenta) SEBAGAI STABILIZER TERHADAP VISKOSITAS DAN UJI ORGANOLEPTIK YOGURT
}

\author{
Aju Tjatur Nugroho Krisnaningsih ${ }^{1}$, Tri IdaWahyu Kustyorini ${ }^{1}$, Magdalena Meo ${ }^{1}$ \\ ${ }^{1}$ Fakultas Peternakan Universitas Kanjuruhan Malang \\ Email: ajutjatur@unikama.ac.id
}

\begin{abstract}
Tujuan dari penelitian untuk mengetahui pengaruh penambahan pati talas (Colocasia esculenta) sebagai stabilizer terhadap viskositas dan uji organoleptik yogurt. Materi yang digunakan dalam penelitian ini adalah susu sapi segar, pati talas, susu skim, dan starter. Metode penelitian yang digunakan adalah percobaan Laboratorium dengan menggunakan Rancangan Acak Lengkap (RAL) yang terdiri dari 4 perlakuan yaitu: P0 0\%, P1 0,5\%, P2 1\%, P3 1,5\%, penambahan pati talas, masing-masing perlakuan diulang 3 kali. Data yang diperoleh dianalisis dengan analisis ragam, apabila terdapat perbedaan maka dilanjutkan dengan uji Beda Nyata Terkecil (BNT). Variabel yang diamati meliputi: viskositas dan uji organoleptik yogurt. Hasil penelitian menunjukkan bahwa pengaruh penambahan pati talas (Colocasia esculenta) sebagai stabilizer memberikan perbedaan yang sangat nyata $(\mathrm{P}<0,01)$ terhadap viskositas dan kesukaan tekstur yogurt. Nilai viskositas tertinggi dengan penambahan pati $1,5 \%$ sebesar $8230 \mathrm{cP}$, selanjutnya berturut-turut level 1\%, 0,5\%, $\%$ sebesar $1880 \mathrm{cP}, 1240 \mathrm{cP}$, dan $830 \mathrm{cP}$. Pada kesukaan tekstur yogurt nilai tertinggi adalah penambahan pati $1,5 \%$ dengan skor 9,0 dan nilai terendah yaitu $0 \%$ dengan skor nilai 6,8 . Sedangkan penambahan pati tidak memberi pengaruh $(\mathrm{P}>0,05)$ terhadap warna, rasa dan aroma yogurt. Pada kesukaan warna nilai tertinggi dengan penambahan level pati $0,5 \%$ sebesar 7,4 dan nilai terendah dengan penambahan pati $1 \%$ dengan skor 7. Pada kesukaan rasa nilai tertinggi dengan penambahan level pati $0,5 \%$ sebesar 6,47 dan nilai terendah yaitu dengan penambahan pati 1,5\% sebesar 5,53. Pada kesukaan aroma yogurt nilai tertinggi dengan level pati $0 \%$ dan $0,5 \%$ sebesar 7,4 dan nilai dengan penambahan pati $1 \%$ dan $1,5 \%$ dengan skor 7,3 . Berdasarkan hasil penelitian dapat disimpulkan bahwa penambahan pati talas sebagai stabilizer sebesar 1,5\% menghasilkan kualitas yogurt yang optimal ditinjau dari viskositas dan kesukaan tekstur yogurt.
\end{abstract}

Kata kunci: pati talas, stabilizer, viskositas, organoleptik, yoghurt

\section{ABSTRACT}

The aim of this research was to know effect of adding the taro starch (Colocasia esculenta) as a stabilizer on viscosity and organoleptik test. The research method used was a laboratory experiment using a completely randomized desing (CRD), which consists of 4 treatments $(\mathrm{P} 0=$ without the addition of taro starch, $\mathrm{P} 1=$ addition of taro starch $0,5 \%, \mathrm{P} 2=$ addition of taro starch $1 \%, \mathrm{P} 3=$ addition of taro starch 1,5\%) and 3 replications, then continued by Least Significant Difference (LSD). The result showed that the addition of taro starch as a stabilizer provides highly significant effect $(\mathrm{P}<0,01)$ on the viscosity and texture yogurt. Result showed the highest viscosity values by adding starch $1,5 \%=8230 \mathrm{cP}$ and the lowest score without the addition of starch is $0 \%=830 \mathrm{cP}$. An texture of yogurt on the highest volue with the addition of taro starch $1,5 \%$ with a score of 9 and the lowest rate of $0 \%$ was 6,8 . While adding starch not have the effect of $(\mathrm{P}>0,05)$ in color, taste and flavor. The highest score is of a favorite by adding starch $0,5 \%=7,4$ and the lowest $1 \%=7,0$. Favorit yogurt on the highest score is adding starch $0,5 \%=6,47$ and the lowest $1,5 \%=5,53$. On fondnes scent highest score by adding starch $0 \%$ and $0,5 \%=7,4$ and the lowest value adding starch $1 \%$ and $1,5 \%=7,3$. It was concluded that the addition of taro starch as a stabilizer of $1.5 \%$ produces yogurt optimum quality in terms of viscosity and texture of yogurt. Keywords: yogurt, taro starch, viscosity, organoleptic test.

\section{Pendahuluan}

Yoghurt merupakan susu fermentasi yang dihasilkan dengan bantuan Bakteri Asam Laktat (BAL). BAL tersebut adalah Lactobacillus bulgaricus dan Streptococcus thermophilus yang mampu menghidrolisa laktosa, sehingga mengakibatkan susu menjadi asam. Keasaman yang dihasilkan mampu menghambat bakteri penyebab penyakit 


\section{Jurnal Sains Peternakan}

Volume 8 No. 1, Juni 2020, pp:66-76

ISSN 2579-4450

(patogen) yang umumnya tidak tahan terhadap asam (Ferdian, 2011). Adanya bakteri asam laktat inilah yang mebuat rasa asam dan aroma khas yogurt, bukan saja karena cita rasanya yang spesifik, tetapi yogurt memiliki peranan penting bagi kesehatan tubuh (Legowo, 2009).

Kelemahan produk yogurt yaitu pada proses pembuatannya terjadi penurunan daya ikat air (whey off), hal ini disebabkan $\mathrm{pH}$ yoghurt berada dikisaran titik isoelektrik kasein. Gel kasein yang berada pada lingkungan $\mathrm{pH}$ isoelektrik mempunyai daya pengikatan molekul air yang relatif lemah, mendorong pelepasan molekul air pada permukaan gel atau sineresis dan penurunan viskositas / kekentalan (Alakali, Okonkwo, and Iordye, 2008). Penurunan daya ikat air ini dapat mempengaruhi kualitas produk akhir yogurt. Alternatif untuk mengantisipasi masalah ini dengan cara menambahkan stabilizer (Agarwal and Prasad, 2013). Selain mampu untuk mengikat air yang merupakan media pertumbuhan bakteri, fungsi stabilizer yang lain yaitu dapat meningkatkan masa simpan yogurt dengan menekan pertumbuhan bakteri pembusuk (Utomo, Purwadi, dan Thohari, 2013 ).

Penambahan salah satu bahan stabilizer baik alami maupun buatan diperlukan untuk mempertahankan kualitas yogurt dengan waktu simpan yang lebih lama. Salah satu bahan stabilizer alami adalah umbi porang (Amorphopallus oncophyllus). Tamine and Robinson (2000) menyatakan bahwa tujuan utama penambahan bahan penstabil pada yogurt adalah untuk meningkatkan dan mempertahankan sifat karakteristik yogurt yang diinginkan, seperti viskositas, konsistensi, penampakan dan rasa yang khas. Peranan utama dari bahan penstabil terdiri atas dua tahap yaitu pertama pengikat air, dan yang kedua meningkatkan viskositas yogurt.

Tumbuhan talas dapat dimaanfaatkan sebagai salah satu bahan pangan sumber kalori dan non beras Kusumo (2002). Menurut Rahmawati (2012), kadar pati merupakan kriteria mutu terpenting pada tepung baik sebagai bahan pangan maupaun non pangan. Kadar pati yang dihasilkan pada umbi talas sekitar $80 \%$ dan kadar pati pada tepung talas sekitar $75 \%$. Pemanfaatan talas sebagai tepung talas maupun pati talas akan meningkatkan nilai ekonomis dan daya simpan produk talas. Selain dapat digunakan sebagai bahan pangan pengganti beras, talas juga dapat digunakan sebagai bahan stabilizer dalam pembuatan yogurt drink. Menurut hasil penelitian Utomo, Purwadi, dan Thohari (2013) menunjukkan bahwa penambahan stabilizer alami umbi porang (Amorphophallus oncophyllus) menghasilkan kualitas yogurt drink lebih baik selama penyimpanan pada refrigerator dibandingkan penggunaan stabilizer gelatin ditinjau dari TPC, viskositas, sineresis dan $\mathrm{pH}$. 


\section{Jurnal Sains Peternakan}

Volume 8 No. 1, Juni 2020, pp:66-76

ISSN $2579-4450$

Pati merupakan sumber padatan dengan molekul amilopektin yang rapat dan berdaya serap air tinggi (Hartati dan Prana, 2003), sehingga dapat menghasilkan produk dengan tingkat kepadatan yang tinggi terhadap yogurt. Berdasarkan kajian diatas sehingga diperlukan penelitian terkait "pengaruh penambahan pati talas (Colocasia esculenta) sebagai stabilizer terhadap viskositas dan uji organoleptik".

\section{Materi Dan Metode}

Materi dalam penelitian ini adalah susu, pati talas, starter dan susu skim. Metode penelitian yang digunakan adalah percobaan laboratorium. Prosedur pembuatan pati talas dan yogurt disajikan pada Gambar 1 dan 2.

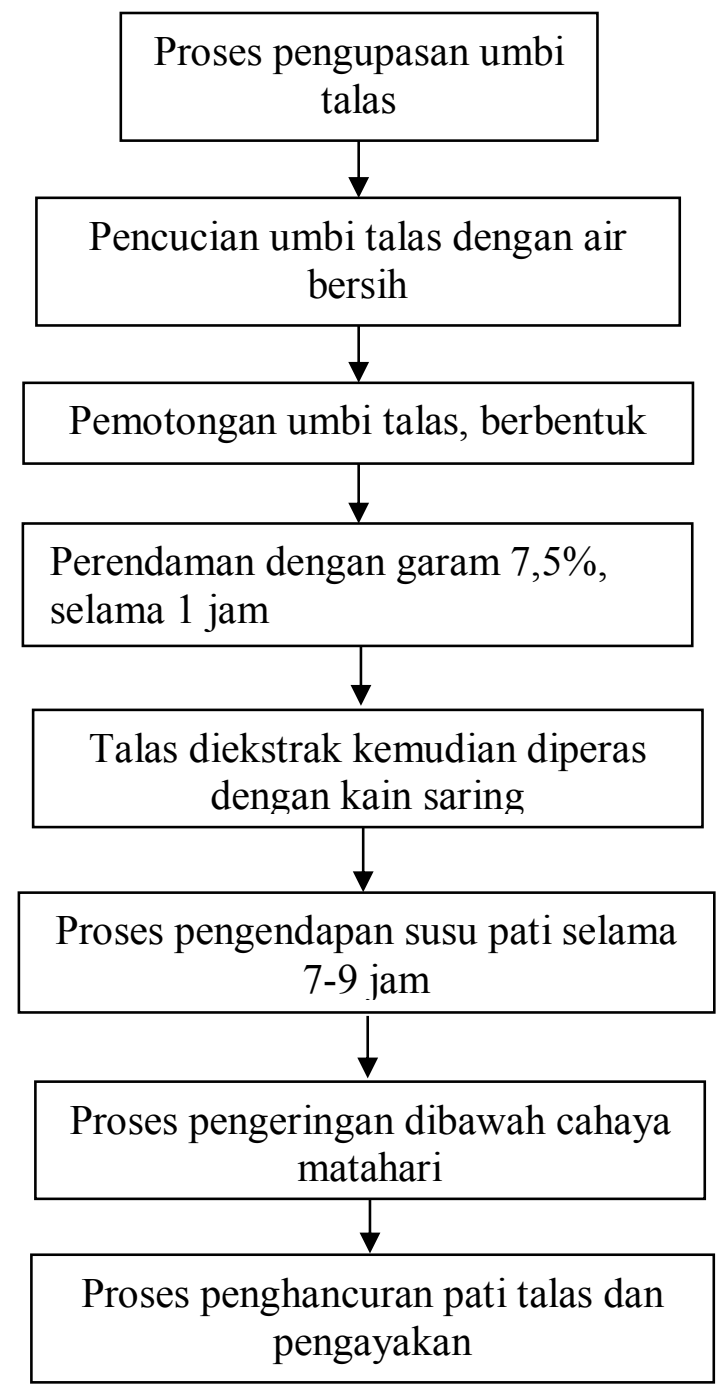

Gambar 1. Proses Pembuatan pati 


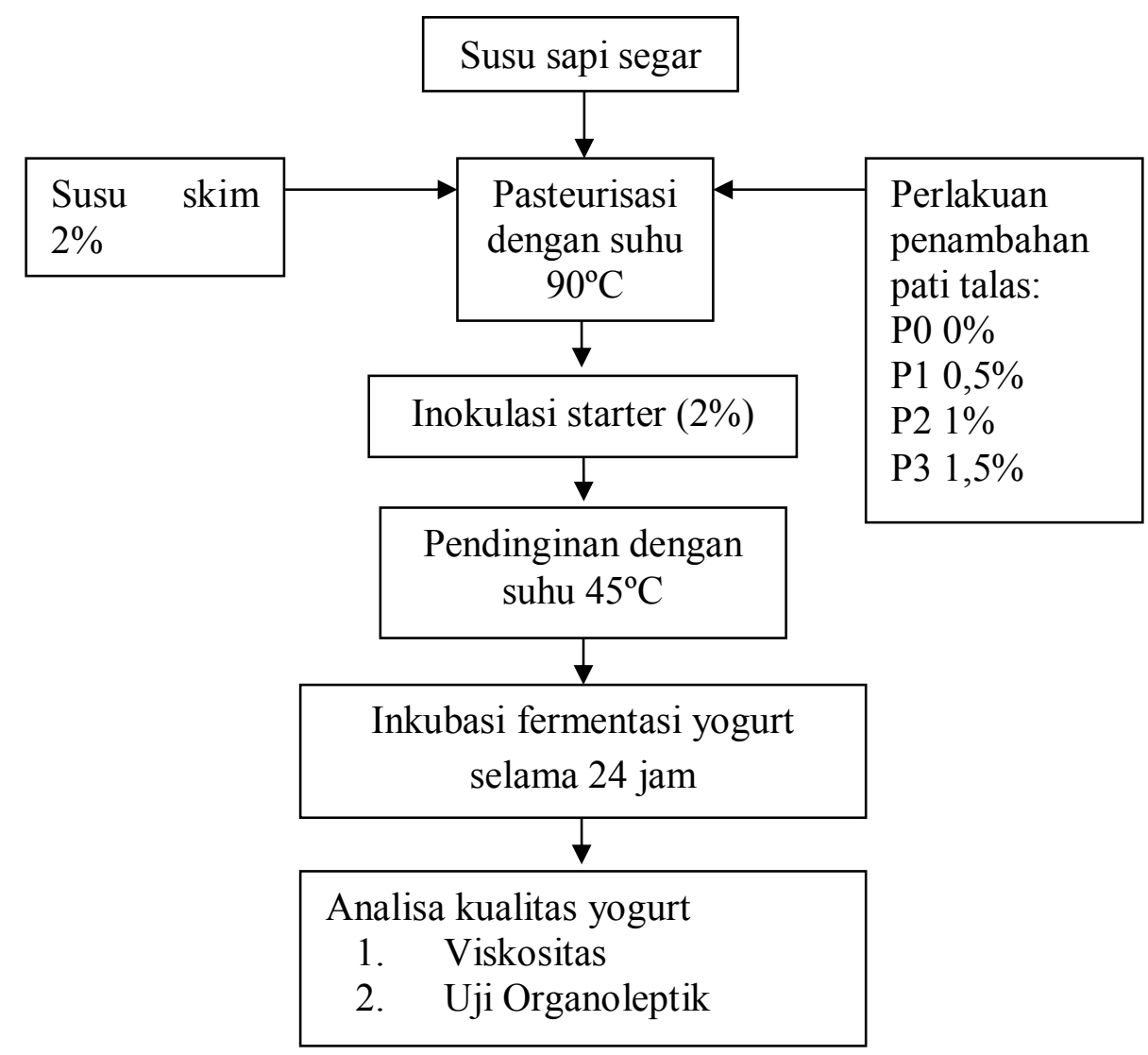

Gambar 2. Proses Pembuaran Yogurt

Penelitian ini terdiri dari 4 perlakuan yaitu:

P0 $=$ susu pasteurisasi $+\operatorname{susu} \operatorname{skim}(2 \%)+$ pati talas $0 \%$ (kontrol)

$\mathrm{P} 1=$ susu pasteurisasi + susu skim $(2 \%)+$ pati talas $0,5 \%$

$\mathrm{P} 2=$ susu pasteurisasi + susu skim $(2 \%)+$ pati talas $1 \%$

P3 $=$ susu pasteurisasi + susu skim $(2 \%)+$ pati talas $1,5 \%$

Masing-masing perlakuan diulang sebanyak 3 kali.

Variabel yang diukur dalam penelitian ini adalah:

a Viskositas

Pengujian viskositas dalam penelitian ini diawali dengan pengujian berat jenis susu menggunakan piknometer.

b Uji Organoleptik

Pengujian kesukaan dalam penelitian ini akan dilakukan oleh 15 panelis.

Data hasil penelitian dianalisis dengan menggunakan analisis ragam, apabila perlakuan memberikan pengaruh maka dilanjutkan uji Beda Nyata Terkecil (BNT). 


\section{Jurnal Sains Peternakan}

Volume 8 No. 1, Juni 2020, pp:66-76

ISSN 2579-4450

\section{Hasil Dan Pembahasan}

Susu sapi segar diperoleh dari Koperasi Unit Desa Pujon, data pengamatan susu sapi segar dari segi fisik dan $\mathrm{pH}$ dapat dilihat pada Tabel 1.

Tabel 1. Kualitas Susu Segar Bahan Penelitian

\begin{tabular}{lr}
\hline Karakteristik susu sapi segar & Hasil pengamatan \\
\hline $\mathrm{pH}$ & 6,6 \\
Warna & Putih \\
Rasa & Biasa \\
Aroma & Khas susu \\
Tekstur & Cair \\
\hline \multicolumn{2}{c}{ Rata-rata nilai pH susu dalam penelitian sebesar 6,6 pengamatan secara fisik }
\end{tabular}

memiliki warna putih, bau khas susu, berbentuk cair tanpa gumpalan dan memiliki rasa normal susu. Nilai pH 6,6 disebabkan susu masih dalam keadaan segar dan belum mengalami pencemaran oleh mikroorganisme atau bahan lain yang dapat merusak kualitas susu. SNI 3141.1:2011 (Badan Standardisasi Nasional, 2011) menyatakan bahwa syarat mutu susu sapi segar memiliki pH 6,3-6,8 karakteristik warna, bau, rasa, dan kekentalan tidak ada perubahan. $\mathrm{pH}$ susu segar berada di antara 6,6-6,7 dan bila terjadi cukup banyak pengasaman oleh aktivitas bakteri, angka-angka ini akan menurun secara nyata.

\section{Pengaruh Penambahan Pati Talas terhadap Viskositas Yogurt}

Viskositas adalah ukuran kekentalan suatu bahan pangan. Berdasarkan hasil penelitian penambahan pati dari umbi talas memberi pengaruh yang sangat nyata $(\mathrm{P}<0,01)$ terhadap viskositas yogurt. Rata-rata viskositas yogurt tertera pada Tabel 2. dan Gambar 3.

Tabel 2. Rata-rata viskositas yogurt

\begin{tabular}{lr}
\hline Perlakuan & Rata-rata (cP) \\
\hline P0 & $830,00 \pm 20^{\mathrm{a}}$ \\
P1 & $1240,00 \pm 20^{\mathrm{b}}$ \\
P2 & $1880,00 \pm 20^{\mathrm{c}}$ \\
P3 & $8230,00 \pm 20^{\mathrm{d}}$ \\
\hline Keterangan: Notasi yang berbeda & a-d dalam kolom yang sama menunjukkan bahwa \\
& penambahan pati talas memberi pengaruh yang sangat nyata $(\mathrm{P}<0,01)$ \\
& terhadap viskositas yogurt.
\end{tabular}




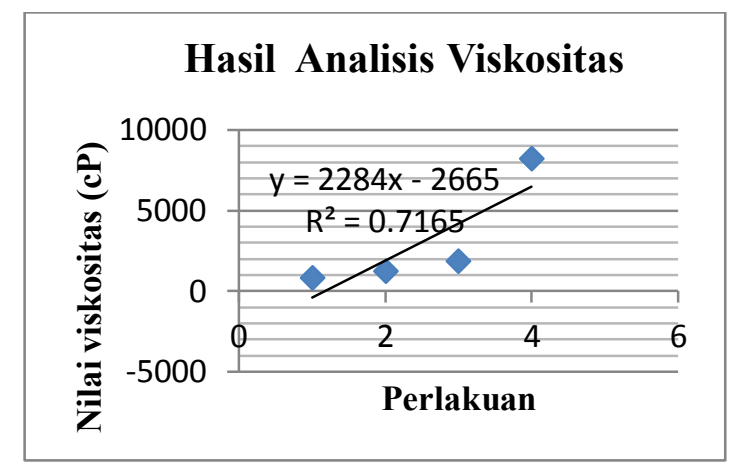

Gambar 3. Rata-rata nilai viskositas

Pada perlakuan P3 dengan penambahan pati (1,5\%) memberikan viskositas tertinggi sebesar $8230 \mathrm{cP}$, kemudian perlakuan $\mathrm{P} 2$, P1, P0 dengan penambahan pati talas (1\%), (0,5\%), dan (0\%) sebesar $1880 \mathrm{cP}, 1240 \mathrm{cP}, 830 \mathrm{cP}$. Hal ini disebabkan karena adanya penambahan pati pada pembuatan yogurt. Berdasarkan hasil tersebut dapat kita ketahui bahwa semakin tinggi level pati yang diberikan pada produk yogurt maka semakin meningkat pula nilai viskositas yogurt itu sendiri. Concalves, Perez dan Cambaro (2005) menyatakan bahwa semakin banyaknya konsentrasi pengental, kapasitas pengikatan air juga akan semakin meningkat. Rauf dan Sarbini (2012), menyatakan semakin tinggi bahan penstabil maka makin tinggi viskositasnya. Hasil penelitian Alkali, Okankwo, Lordye (2008) menyatakan bahwa makin tinggi konsentrasi bahan penstabil, semakin tinggi viskositasnya. Hal ini disebabkan karena didalam pati terkandung amilosa dan amilopektin yang mampu mengikat air dalam yogurt. Hal ini sesuai dengan pendapat (Hartati dan Prana, 2003) bahwa pati merupakan sumber padatan dengan molekul amilopektin yang rapat dan berdaya serat air tinggi, sehingga dapat menghasilkan yogurt dengan viskositas yang tinggi. Selain itu pati talas juga memiliki keunggulan patinya untuk dicerna hal ini disebabkan pati talas memiliki ukuran granula yang sangat kecil 1-4 $\mu \mathrm{m}$. Menurut Setyowati dkk (2007) mengatakan bahwa ukuran granula pati yang kecil bermanfaat mengatasi masalah pencernaan.

\section{Pengaruh Penambahan Pati Talas terhadap Organoleptik Warna Yogurt}

Warna merupakan salah satu parameter fisik suatu bahan pangan yang penting, kesukaan konsumen terhadap produk pangan juga ditentukan oleh warna pangan tersebut. Rahayu (2001) menjelaskan bahwa warna bisa menjadi parameter kualitas yang dipertimbangkan oleh konsumen sebelum menilai mutu organoleptiknya. Berdasarkan hasil analisa statistik dapat kita ketahui bahwa penambahan pati talas tidak berpengaruh $(\mathrm{P}>0,05)$ pada kesukaan warna yogurt. Hasil rata-rata nilai uji hedonik terhadap warna dari masing-masing perlakuan tertera pada Tabel 3. 


\section{Jurnal Sains Peternakan}

Volume 8 No. 1, Juni 2020, pp:66-76

ISSN 2579-4450

Tabel 3. Rata-rata Nilai Kesukaan Warna Yogurt

\begin{tabular}{lr}
\hline Perlakuan & Nilai \\
\hline P0 & $7,2 \pm 0,70$ \\
P1 & $7,4 \pm 1,55$ \\
P2 & $7,0 \pm 1,07$ \\
P3 & $7,2 \pm 0,70$ \\
\hline Keterangan: penambahan pati talas tidak memberi pengaruh $(\mathrm{P}>0,05)$ terhadap \\
\multicolumn{2}{l}{ kesukaan warna yogurt. }
\end{tabular}

Nilai tertinggi tingkat kesukaan panelis terhadap warna yogurt ini diperoleh pada perlakuan P1 (penambahan pati talas 0,5\%) dengan skor 7,4 kemudian diikuti P0, P3, P2 dengan penambahan pati talas $(0 \%),(1,5 \%)$, dan $(1 \%)$ sebesar $7.2,7,2,7$. Hal ini disebabkan karena warna yogurt yang dihasilkan sama yaitu berwarna putih. Penambahan pati talas tidak memberi pengaruh terhadap warna yogurt, karena pati talas berwarna putih dan susu segar yang digunakan sebagai bahan dasar juga berwarna putih, sehingga kombinasi warna yang dihasilkan rerata sama.Sesuai dengan pernyataan Koswara (2014), pati ubi yang baik adalah yang berwarna putih. Rahayu(2001), menambahkan bahwa yogurt pada umumnya berwarna putih.

\section{Pengaruh Penambahan Pati Talas terhadap Organoleptik Rasa Yogurt}

Rasa merupakan salah satu hal yang paling penting dalam menentukan tingkat penerimaan terhadap suatu produk bahan makanan. Berdasarkan hasil analisa statistik dapat kita ketahui bahwa penambahan pati talas tidak memberi pengaruh $(\mathrm{P}>0,05)$ terhadap kesukaan rasa yogurt. Hasil rata-rata nilai uji hedonik terhadap rasa dari masing-masing perlakuan tertera pada Tabel 4.

Tabel 4. Rata-rata Nilai Kesukaan Rasa Yogurt

\begin{tabular}{lr}
\hline Perlakuan & Nilai \\
\hline P0 & $6.07 \pm 1,83$ \\
P1 & $6,47 \pm 2,20$ \\
P2 & $6,20 \pm 2,11$ \\
P3 & $5,53 \pm 1,60$ \\
\hline Keterangan: penambahan pati talas tidak memberikan pengaruh $(\mathrm{P}>0,05)$ terhadap \\
kesukaan rasa yogurt. \\
Berdasarkan Tabel 4. dapat kita lihat bahwa tingkat kesukaan panelis terhadap \\
rasa dari yogurt lebih tinggi pada perlakuan P1 dengan penambahan pati talas 0,5\% dan \\
skor yang didapat 6,47 kemudian diikuti secara berturut-turut yaitu P2, P0, P3 dengan \\
penambahan pati talas 1\%, 0\%, 1.5\% dan skor yang diperoleh yaitu 6,20, 6,07 dan 5,53. \\
Rasa asam yoghurt berasal dari BAL yang menghidrolisa pati dan laktosa menjadi asam \\
laktat dan berbagai asam-asam lain. Rashid dan Thakur (2012) menambahkan bahwa rasa
\end{tabular}




\section{Jurnal Sains Peternakan}

Volume 8 No. 1, Juni 2020, pp:66-76

ISSN 2579-4450

khas yoghurt disebabkan karena asam laktat, asetal dehida, diasetil, asam asetat dan bahan-bahan mudah menguap lainnya yang dihasilkan oleh fermentasi bakteri.

\section{Pengaruh Penambahan Pati Talas terhadap Organoleptik Aroma Yogurt}

Aroma merupakan salah satu faktor penting dalam menentukan kesukaan dari panelis yang dipengaruhi oleh senyawa hasil fermentasi. Berdasarkan hasil analisis statistik menunjukkan bahwa penambahan pati talas tidak memberikan pengaruh $(\mathrm{P}>0,05)$ terhadap kesukaan aroma. Nilai rata-rata kesukaan yogurt terhadap aroma tertera pada Tabel 5.

Tabel 5. Rata-rata Nilai Kesukaan Aroma Yogurt

\begin{tabular}{lr}
\hline Perlakuan & Nilai \\
\hline P0 & $7,4 \pm 1,12$ \\
P1 & $7,4 \pm 1,12$ \\
P2 & $7,3 \pm 1,03$ \\
P3 & $7,3 \pm 1,03$ \\
\hline & kesukaan aroma yogurt.
\end{tabular}

Pati talas yang ditambahkan pada proses fermentasi yoghurt tidak memiliki aroma yang khas seperti layaknya pati umbi lainnya. Proses perendaman dan pengeringan pati diduga telah menguraikan zat aroma pada pati yang dihasilkan. Hasil penelitian menunjukan bahwa nilai tertinggi terdapat pada perlakuan P0 dan P1 dengan skor 7,4 dan penilaian terendah terdapat pada perlakuan P2 dan P3 dengan skor 7,3. Hal ini membuktikan bahwa pati talas yang ditambahkan dalam pembuatan yogurt ini memang tidak mempengaruhi aroma yang dihasilkan. Aroma yang mendominasi berasal dari aroma asam yoghurt. Aroma asam pada yoghurt, muncul akibat adanya penurunan $\mathrm{pH}$ yang disebabkan oleh aktivitas BAL yang merombak pati dan laktosa menjadi asam laktat dan asam-asam lain seperti asetaldehid dan diasetil. Kedua asam inilah yang berperan dalam pembentukan aroma asam pada yoghurt. Asetaldehid akan mulai terbentuk saat proses fermentasi mencapai $\mathrm{pH}$ 5. Yoghurt yang dihasilkan dalam penelitian juga tidak ditambahkan dengan bahan tambahan seperti perasa yang dapat merubah aroma alami yogurt. Pada dasarnya aroma yogurt tersebut disebabkan terbentuk senyawa lain selain asam laktat yaitu asetat, senyawa ini merupakan senyawa yang bersifat volatil dan mempunyai aroma yang kuat, sedangkan asam laktat bersifat tidak dapat dicium atau bersifat adouries (Anonimus, 2010). Menurut Ikrin dan Eren (2008) bahwa L. bulgaricus lebih berperan dalam pembentukan aroma, sedangkan $S$. thermophilus lebih berperan pada citarasa yogurt. Substansi yang dihasilkan oleh bakteri asam laktat dan komponen volatil memberikan karakteristik asam dan aroma yogurt (Widodo, 2002). 


\section{Jurnal Sains Peternakan}

Volume 8 No. 1, Juni 2020, pp:66-76

ISSN 2579-4450

\section{Pengaruh Penambahan Pati Talas terhadap Organoleptik Tekstur Yogurt}

Tekstur merupakan bagian terpenting dalam menilai mutu suatu bahan makanan selain warna, rasa dan aroma. Berdasarkan hasil analisis statistik menunjukan bahwa penambahan pati talas memberikan pengaruh yang sangat nyata $(\mathrm{P}<0,01)$ terhadap kesukaan tekstur yogurt. Nilai rata-rata kesukaan tekstur yogurt tertera pada Tabel 8 dan Gambar 6 .

Tabel 6. Rata-rata Nilai Kesukaan Tekstur Yogurt.

\begin{tabular}{lr}
\hline Perlakuan & Nilai \\
\hline P0 & $6,8 \pm 0,52^{\mathrm{a}}$ \\
P1 & $7,4 \pm 1,55^{\mathrm{a}}$ \\
P2 & $8,6 \pm 0,83^{\mathrm{b}}$ \\
P3 & $9,0 \pm 0,00^{\mathrm{b}}$ \\
\hline \multicolumn{2}{r}{ Keterangan:Notasi yang berbeda a-b dalam kolom yang sama menunjukkan bahwa } \\
\multicolumn{2}{l}{ penambahan pati talas memberikan pengaruh yang sangat nyata $(\mathrm{P}<0,01)$} \\
& tehadap kesukaan tekstur yogurt.
\end{tabular}

Kesukaan terhadap tekstur tertinggi pada perlakuan P3 (1,5\%) dan P2 (1\%) dengan rata-rata kesukaan sebesar 9 dan 8,6, sedangkan nilai yang paling rendah yaitu pada $\mathrm{P} 0(0 \%)$ dengan rata-rata 6,8 , dari hasil tersebut dapat kita ketahui bahwa perbedaan konsentrasi pati dapat memberikan pengaruh terhadap tekstur yogurt, hal ini disebabkan karena terjadi penurunan $\mathrm{pH}$ sehingga yogurt menjadi kental. Padatan total dalam susu juga berperan untuk pembentukan tekstur dan aroma yogurt yang baik (Widodo, 2003).

Peningkatan tekstur disebabkan karena adanya penambahan pati, didalam pati terkandung molekul penyusun yaitu amilosa dan amilopektin yang berfungsi sebagai pengikat air. Hal ini sesuai dengan pendapat Mikasari dan Ivanti (2013) bahwa pati merupaakan sumber padatan dengan molekul amilopektin yang rapat dan berdaya serat air tinggi, sehingga berpengaruh terhadap tekstur yogurt. Molekul penyusun pati adalah amilosa dan amilopektin dengan perbandingan amilosa 25\% dan amilopektin 75\% (Poedjiadi, 2006).

Gambar 4. Nilai Rata-Rata Kesukaan Tekstur Yogurt

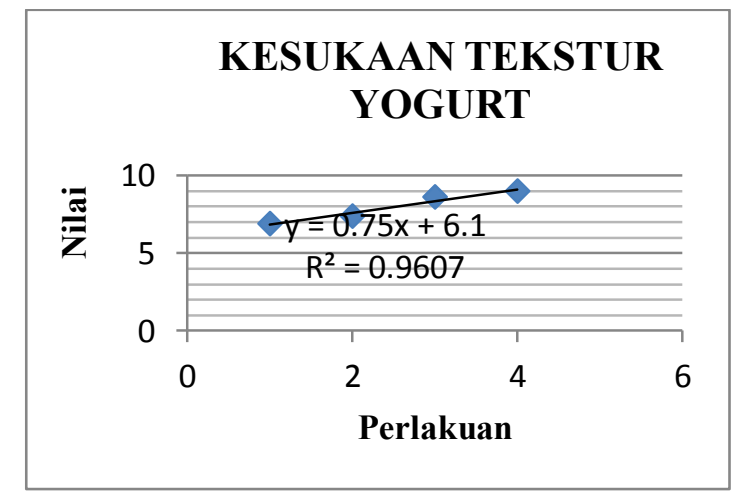

Gambar 4. Rata-rata nilai tekstur yogurt 


\section{Kesimpulan}

Kesimpulan dari hasil penelitian ini yaitu penambahan pati talas sebagai stabilizer sebesar 1,5\% menghasilkan kualitas yogurt yang optimal ditinjau dari viskositas dan kesukaan tekstur yogurt.

\section{Daftar Rujukan}

Agarwal, S and Prasad, R. 2013. Effect of Stabilizer on Sensory Characteristics and Microbial Analysis of Low-fat Frozen Yoghurt Incoporated with Carrot Pulp. International Journal of Agriculture and Food Science Technology. ISSN 2249-3050, Volume 4, Number 8 (2013), pp. 797-806

(C) Research India Publications

Alakali, J. S, Okonkwo, T. M. and Iordye, E. M. 2008. Effect of stabilizers on the physico-chemical and sensory attributes of thermized yoghurt. African Journal of Biotechnology Vol. 7 (2), pp. 158-163, 18 January, 2008 Available online at http://www.academicjournals.org/AJB

Anonimus. 2010. Teknologi Pangan dan Agroindustri, volume 1 nomor 6. Bogor IPB. Jurusan Teknologi Pangan dan Gizi.

Badan Standardisasi Nasional. SNI 3141.1: 2011. Susu Segar. Bagian 1: Sapi. 2011. Jakarta

Concalves. D., C. Perez, C. Reolon, N. Segura, P. Lema, A. Camboro, P. Varela and C. Ares. 2005. Effect of Thickener on the Texture of Stirred Yogurt. Alim. Nutr. Araraquara. 16 (3): 207-211

Ferdian, A. 2011. Pengaruh Bubuk Bubuk Cokelat Fermentasi pada Yoghurt Susu Kambing Menggunakan Starter Lactobacillus fermentum dan Streptococcus thermophilus terhadap Kadar Air, Keasaman dan Mikrobiologi. Jurnal Fakultas Peternakan Universitas Andalas. Padang. Hartati, N. S. dan T. K. Prana. 2003

Hartati, N. S. dan Prana, T. K. 2003. Analisis kadar pati dan serat kasar tepung beberapa kultivar talas (Colocasia esculenta L. Schott). Natur Indonesia 6(1): 29-33

Koswara, Sutrisno. 2014. Teknologi Pengolahan Umbi-Umbian Bagian 5: Pengolahan Umbi Jalar. SEAFAST Center. Research and Community Service Institution Bogor Agricultural University.

Manglayang Farm, 2006. Mikrobiologi Susu dan Yogurt Starter, Ananda Marga, Batam.

Mikasari, W., Ivanti, L. 2013. Sifat Organoleptik dan Kandungan Nutrisi Es Krim Ubi Jalar Varietas Lokal Bengkulu. Balai Pengkajian Teknologi Pertanian Bengkulu.

Poedjiadi, Anna. 2006. Dasar-Dasar Biokimia. Jakarta: UI Press. 


\section{Jurnal Sains Peternakan}

Volume 8 No. 1, Juni 2020, pp:66-76

ISSN 2579-4450

Rahayu, W.P. 2001. Penuntun Pratikum Penilaian Organoleptik. Jurusan Teknologi Pangan dan Gizi. Fakultas Teknologi Pertanian Bogor. Institut Pertanian Bogor. Bogor.

Rahmawati, W. 2012. Karakteristik Pati Talas (Colocasia esculenta (L) Schoot) Sebagai Alternatif Sumber Pati Industri di Indonesia. Jurnal Teknologi Kimia dan Industri. Vol. No. 1: 347-351.

Rashid, A and S. N. Thakur. 2012. Studies on Quality Parameters of Set Yoghurt Prepared by the Addition of Honey. International Journal of Scientific and Research Publications.2 (9): 1-9.

Setyowati, Mamik, Ida Hanarida, dan Sutoro. 2007. Karakteristik Umbi Plasma Nutfah Tanaman Talas (Colocasia esculenta). Balai Besar Penelitian dan Pengembangan Bioteknologi dan Sumberdaya Genetik Pertanian. Bogor.

Tamine, A. Y. and R. K. Robinson. 2000. Yogurt Science and Teknology. Second Edition. Woodhead Publishing Limited, England.

Utomo, M.S.,Purwadi, dan I. Thohari.2013. Pengaruh Tepung Porang (Amorphophallus Oncophyllus) Terhadap Kualitas Yoghurt Drink Selama Penyimpanan Pada Refrigerator Ditinjau Dari TPC, Viskositas, Sineresis Dan PH. Jurnal IlmuIlmu Peternakan. Vol 23, No 2 (2013)

Widodo. W. 2002. Bioteknologi Fermentasi Susu. Universitas Muhamadiyah Malang. Malang. 